ARTIGO DE REVISÃO

\title{
VIROIDES, PEQUENOS RNAS PATOGÊNICOS CAPAZES DE REPLICAÇÃO AUTÔNOMA: MODELOS MOLECULARES PARA O ESTUDO DE INTERAÇÕES PATÓGENO-HOSPEDEIRO E EVOLUÇÃO
}

\begin{abstract}
M. Eiras
Instituto Biológico, Centro de Pesquisa e Desenvolvimento de Sanidade Vegetal, Av. Cons. Rodrigues Alves, 1252, CEP 04014-002, São Paulo, SP, Brasil. E-mail: eiras@biologico.sp.gov.br
\end{abstract}

\section{RESUMO}

\begin{abstract}
Os viroides, apesar de serem constituídos por um pequeno RNA de fita simples, fortemente estruturado, circular, que não codifica proteínas, são capazes de se replicar de maneira autônoma em plantas superiores e causar doença interagindo diretamente com fatores do hospedeiro. Nesta revisão, serão apresentados e discutidos alguns dos mais recentes trabalhos envolvendo a interação de viroides com fatores do hospedeiro, incluindo aspectos relacionados à replicação, movimento e patogênese, além de suas características evolutivas. Nos últimos anos, alguns grupos de pesquisa têm se aventurado na busca por fatores do hospedeiro e mecanismos moleculares relacionados ao ciclo infeccioso dos viroides, tentando desvendar como esses pequenos RNAs interagem com o hospedeiro induzindo sintomas. Os viroides não codificam proteínas supressoras de silenciamento e, portanto, devem garantir sua existência utilizando estratégias baseadas em sua estrutura secundária, na compartimentalização em organelas, associação com fatores do hospedeiro e eficiência na replicação. A complexidade do ciclo infeccioso desses minúsculos RNAs indica que muitas interações desses patógenos com fatores do hospedeiro ainda devem ser identificadas.
\end{abstract}

PALAVRAS-CHAVE: Avsunviroidae, Pospiviroidae, Silenciamento de RNA, L5, TFIIIA.

\section{ABSTRACT}

VIROIDS, SMALL PATHOGENIC RNAs CAPABLE OF AUTONOMOUS REPLICATION: MOLECULAR MODELS FOR THE STUDY ON HOST-PATHOGEN INTERACTIONS AND EVOLUTION. Viroids are small, single-stranded, highly structured, circular RNAs that replicate autonomously in their hosts, without messenger RNA activity. Because they do not encode for proteins, viroids have to interact directly with host factors. This review presents recent progress in understanding the possible role of recently identified viroid-binding host proteins related to replication, trafficking and pathogenesis. It also discusses some aspects on viroid evolution. In recent years, efforts to understand how viroids replicate, cause disease and induce symptoms have prompted details on molecular mechanisms related to the viroid infectious cycle. Inasmuch as viroids lack protein-encoding capacity, including suppressors of gene silencing, their existence could be ensured by their compact conformation, compartimentalization in organelles, association with host factors or by their highly efficient replication. The complexity of the infectious cycle of these tiny pathogenic RNAs indicates that several interactions with host factors remain to be identified.

KEY WORDS: Avsunviroidae, Pospiviroidae, RNA silencing, L5, TFIIIA.

Os viroides são uma classe especial de fitopatógenos com genoma constituído exclusivamente por um pequeno RNA com tamanho que oscila entre 246 e 401 nucleotídeos, circular, fortemente estruturado (devido aos pareamentos de bases), que não codifica proteínas, sendo, porém, capaz de se replicar de maneira autônoma em hospedeiros suscetíveis. As quase 30 diferentes espécies de viroides que infectam exclusivamente plantas superiores são classificadas em duas famílias e oito gêneros de acordo com propriedades biológicas e moleculares (FLORES; OwENS,
2008). A maioria dos viroides pertence à família Pospiviroidae, e como o Potato spindle tuber viroid (PSTVd), espécie tipo desta família [ver para uma revisão OWEns (2007)], contém cinco domínios estruturais [terminal esquerdo ("TL"), Patogenicidade ("P"), Central (" $\left.\mathrm{C}^{\prime \prime}\right)$, incluindo uma região central conservada (CC R), variável ("V") e terminal direito ("TR")] e replica-se no núcleo das células infectadas seguindo um mecanismo de círculo rolante assimétrico que envolve a RNA polimerase II dependente de DNA. A replicação segue uma via exclusiva de 
RNA, sem intermediários de DNA. As moléculas de polaridade $(+)$ do PSTVd acumulam-se no nucléolo e nucleoplasma, enquanto que as de polaridade (-) localizam-se somente no nucleoplasma, sugerindo que a transcrição das fitas de ambas as polaridades ocorre no nucleoplasma, sendo as fitas (+) transferidas e processadas no nucléolo. À família Avsunviroidae pertencem os viroides que não possuem $C C R$ e que se autoclivam por meio de ribozimas do tipo "cabeça de martelo" durante sua replicação, via círculo rolante simétrico, nos cloroplastos, sendo a espécie tipo o Avocado sunblotch viroid (ASBVd) (FLORES; OWENS, 2008).

Os viroides, portanto, podem ser considerados parasitas da maquinaria transcricional, diferentemente da maioria dos vírus de RNA que se replicam no citoplasma, sendo considerados parasitas da maquinaria de tradução celular. Os viroides apresentam similaridades estruturais e evolutivas com alguns RNA satélites de vírus de plantas e com o Hepatitis delta virus (HDV) que infecta os seres humanos, além de terem em comum a replicação via círculo rolante. Porém, são os únicos com capacidade de completar seu ciclo infeccioso de maneira autônoma, sem codificar proteínas e sem a necessidade de um vírus auxiliar.

Informações adicionais sobre a história, biologia, classificação, patogênese e propriedades moleculares e evolutivas dos viroides podem ser obtidas nas revisões de Flores et al. (2005), DARÒs et al. (2006), EIRAS et al. (2006a), DING; WANG (2009), DING (2009). Na presente revisão serão apresentados e discutidos alguns dos mais recentes trabalhos envolvendo a interação de viroides com fatores do hospedeiro, incluindo aspectos relacionados à replicação, movimento e patogênese, além de suas características evolutivas.

Fatores do hospedeiro e "motivos" estruturais envolvidos na replicação, processamento e movimento dos viroides

Os viroides, ao contrário dos vírus de plantas, não codificam proteínas e, portanto, devem interagir diretamente com fatores da célula hospedeira para completar as etapas do seu ciclo infeccioso que inclui: (i) replicação e processamento, (ii) movimento intra e intercelular (célula a célula e via floema) e (iii) patogênese. Essa característica, aliada ao seu pequeno tamanho e estrutura, faz com que sejam considerados modelos para o estudo dessas interações moleculares (DinG; ITAYA, 2007; KALANTIDIs et al., 2008). Nos últimos anos, alguns grupos de pesquisa têm se aventurado na busca por fatores do hospedeiro e mecanismos moleculares relacionados à replicação, movimento e patogênese dos viroides, sendo alguns desses resultados apresentados a seguir.
Trabalhos pioneiros, realizados a partir do final dos anos 1970, mostraram que o PSTVd forma complexos com histonas e outras proteínas (WoLfF et al., 1985; WERNER et al., 1993). Experimentos com inibidores das RNA polimerases indicaram que a síntese das moléculas do PSTVd, emuito provavelmente de outros viroides nucleares (família Pospiviroidae), é catalisada por uma RNA polimerase II (nuclear) dependente de DNA (FLORES; SEMANCIK, 1982; MÜHLBACH; SÄNGER, 1979), enquanto que a síntese de RNA do ASBVd (família Avsunviroidae) é catalisada por uma RNA polimerase cloroplástica codificada no núcleo (NAVARRo et al., 2000).

Por meio de entrecruzamento com luz UV diretamente em folhas de abacateiro infectado pelo ASBVd e espectrometria de massas, selecionaram-se duas proteínas de cloroplastos (PARBP33 e PARBP35) associadas com o ASBVd, sendo que a primeira delas comporta-se como uma chaperona e facilita a autoclivagem in vitro pelas ribozimas dos RNAs diméricos do ASBVd (DARÒs; FLoRES, 2002).

Em outra abordagem, desenvolveu-se um sistema modelo baseado em plantas de Arabidopsis thaliana transgênicas que expressam transcritos diméricos de viroides da família Pospiviroidae. Esse modelo tem permitido deduzir que o processamento dos oligômeros (RNAs viroidais lineares, intermediários da replicação) é mediado, provavelmente, por uma RNAse do tipo III (uma enzima do tipo Dicer de plantas, DCL) que reconhece uma estrutura palindrômica formada a partir da interação entre domínios de estrutura secundária do tipo grampo, denominados de "hairpin I" (DARÒs; Flores, 2004). Landry; Perreault (2005) também demonstraram que uma porção estruturada em grampo do Peach latent mosaic viroid (PLMVd), viroide da família Avsunviroidae, é substrato para DCLs em extrato de gérmen de trigo. Para os viroides da família Avsunviroidae, que apresentam replicação nos cloroplastos, desenvolveu-se um sistema modelo para o estudo de replicação e processamento em cloroplastos transgênicos de Clamydomonas reinhardtii (MOLINA-SERRANO et al., 2007). Os autores observaram que transcritos diméricos do ASBVd, Chrysanthemum chlorotic mottle viroid (CChMVd) e Eggplantlatentviroid (ELVd) foram expressos, clivados corretamenteecircularizados (em ambas as polaridades). Este modelo poderá auxiliar na busca por fatores do hospedeiro relacionados à replicação dos viroides cloroplásticos.

GAs et al. (2007), em um elegante trabalho empregando 16 mutantes de Citrus exocortis viroid (CEVd, membro da família Pospiviroidae) expressos transgenicamente em Arabidopsis, propuseram um novo modelo para o processamento de viroides nucleares. Os oligômeros, derivados da replicação via círculo rolante, são processados in vivo por meio de uma estrutura secundária de dupla hélice (na 
parte superior do RNA do viroide e flanqueada por nucleotídeos da CCR) que tem sua formação facilitada pelo "hairpin I". O corte da molécula seria realizado por uma RNAse do tipo III, enquanto a sua ligação seria dependente do motivo de estrutura terciária loop $\mathrm{E}$, sendo mediada, provavelmente, por uma RNA ligase ainda não descrita em plantas (GAS et al., 2008).

Comexperimentos de imunoprecipitação, identificaram-se duas proteínas defloema decucurbitáceas (PP2 e CmmLec17) que interagem in vitro e in vivo com o Hop stunt viroid (HSVd, família Pospiviroidae), possivelmente auxiliando o movimento deste viroide via floema (GómeZ; PALLÁs, 2001; Owens et al., 2001; GÓMEZ; PALLÁs, 2004; GÓMEZ et al., 2005). Caracterizou-se também uma proteína de tomateiro, denominada viroid RNA-binding protein 1 (Virp1), que apresenta um sinal de localização nuclear que se une especificamente a um "motivo" denominado "RY" [localizado no domínio "TR" do PSTVd], in vitro e in vivo, com implicação no movimento do viroide para o núcleo (MARTínez de Alba et al., 2003; GozMANOVA et al., 2003). KALANTIDIs et al. (2007) demonstraram que tanto plantas de Nicotiana benthamiana que têm a expressão de Virp1 suprimida, como protoplastos derivados dessas plantas, não puderam ser infectados mecanicamente pelo PSTVd. As plantas de $N$. benthamiana silenciadas para Virp1 não apresentaram diferenças fenotípicas aparentes, o que faz com que o gene que codifica essa proteína seja um candidato em potencial para o desenvolvimento de plantas resistentes aos viroides nucleares (Tsagriset al., 2008).

Recentemente, DubÉ et al. (2009) identificaram seis proteínas que interagem com o PLMVd por meio de hibridização northwestern com extrato de folhas de pessegueiro, parcialmente purificado em cromatografia de coluna de afinidade, seguida de espectrometria de massas. Os autores, por meio de mapeamento com nucleases, sugerem que uma das proteínas identificadas, o fator de elongação 1-alfa (eEF1A), deve se unir a uma porção estruturada da molécula de RNA do PLMVd denominada P1. Vale ressaltar que a porção $\mathrm{P} 1$ está próxima tanto do sítio de ligação e clivagem, como do sítio de início da transcrição, o que reforça ser este um possível sítio de ligação a fatores do hospedeiro.

"Motivos" estruturais presentes nas moléculas de RNA de diferentes viroides também têm sido identificados e caracterizados quanto à sua conformação e principalmente quanto à sua possível função nos mecanismos de processamento ereplicação (DELGADO et al., 2005; KOLONKO et al., 2006; GAs et al., 2007), no movimento intra e intercelular (GozMANOva et al., 2003; QI et al., 2004; ZHONG et al., 2007; 2008) e na patogênese (De la PeÑa; Flores, 2002; Malfitano et al., 2003; RoDio et al., 2007). A identificação desses "motivos" estruturais e fatores do hospedeiro, aliada aos modelos para o estudo dos viroides via plantas ou cloroplastos transgênicos (DARÒs; FLORES, 2004; Molina-SERRANO et al., 2007), poderão auxiliar os viroidologistas a elucidar novos mecanismos e interações moleculares da biologia desses minúsculos RNAs.

\section{Proteínas candidatas a interagir com viroides}

Nos trabalhos de identificação de fatores do hospedeiro associados aos viroides, citados anteriormente, utilizaram-se diferentes métodos para isolar proteínas presentes em complexo com viroides in vitro e/ou in vivo. Em uma abordagem distinta, e principalmente em função de suas propriedades bioquímicas e estruturais, duas proteínas [ribossomal L5 e o fator de transcrição IIIA (TFIIIA)] foram selecionadas como candidatas a interagir com viroides nucleares, principalmente por apresentarem sítios de união ao rRNA $5 S$ de eucariontes, incluindo o loop $\mathrm{E}$. $\mathrm{O}$ loop $\mathrm{E}$ (presente em procariontes, eucariontes e na CCR de alguns membros da família Pospiviroidae) é conservado no PSTVd e está envolvido em replicação, processamento, especificidade do hospedeiro e patogênese (DING; ITAYA, 2007; GAS et al., 2007; DiNG, 2009). Por meio de irradiação UV de folhas de tomateiro infectado pelo PSTVd, confirmou-se que o loop E não só existe in vitro (BRANCH et al., 1985) mas também in vivo (EIRAs et al., 2007; WANG et al., 2007), demonstrando que este motivo deve apresentar importante relevância fisiológica. Resultados com ensaios de união in vitro demonstraram que estas duas proteínas de Arabidopsis unem-se ao PSTVd $(+)$ com a mesma afinidade que se unem in vivo ao seu substrato natural, o rRNA 5S, enquanto que a afinidade pelo ASBVd (+), um viroide cloroplástico que não apresenta o loop $\mathrm{E}$, foi significativamente menor (EIRAs et al., 2006b). As proteínas L5 e TFIIIA devem atuar em diferentes etapas do ciclo infeccioso do PSTVd. L5 está envolvida no transporte núcleocitoplasmático do rRNA 5S, e poderia da mesma forma facilitar a exportação de novas moléculas de polaridade $(+)$ do PSTVd para células vizinhas. Além disso, como a proteína L5 de Arabidopsis se une ao rRNA $5 S$ e se acumula no nucléolo, embora também esteja presente no citoplasma, a união de L5 às moléculas de polaridade $(+)$ do PSTVd poderia mediar a passagem seletiva para o nucléolo. Por outro lado, TFIIIA é um fator de transcrição da RNA polimerase III, requerido especificamente para a transcrição de genes do rDNA 5S, e está envolvido na síntese e acúmulo de rRNA $5 S$ e de proteínas ribossomais. TFIIIA pode se unir ao rRNA $5 S$ e também ao seu gene concentrando-se no núcleo e nucléolo. Esta capacidade de união, tanto a DNA como a RNA, faz do TFIIIA um importante candidato ao envolvimento com aspectos da replicação dos viroides nucleares, 
pelo fato destes viroides necessitarem, muito provavelmente, de proteínas com essas propriedades para serem aceitos como moldes pelas RNA polimerases, que em condições normais, transcrevem RNA a partir de moldes de DNA. O TFIIIA poderia atuar como uma ponte entre o RNA do viroide (molde) e a RNA polimerase (EIRAS, 2006; EIRAs et al., 2011). Estudos complementares deirradiaçãoUV de tecidos infectados seguida de imunoprecipitação ("CLIP", Cross-Linking Immunoprecipitation) com anticorpos monoclonais contra L5 e TFIIIA estão sendo conduzidos para confirmar que as interações entre essas duas proteínas com o PSTVd, demonstradas in vitro, também existem in vivo.

\section{Interação de viroides com fatores envolvidos no silenciamento de RNA: a ponta do iceberg}

Diferentes grupos de pesquisa têm demonstrado que tanto os viroides nucleares como também os cloroplásticos podem ser indutores e alvo da maquinaria de silenciamento gênico pós-transcricional (PTGS). Os marcadores desse fenômeno são os pequenos RNAs interferentes (siRNA, small-interfering $R N A$ ) com tamanho entre 21 e 24 nucleotídeos, derivados da ação de enzimas do tipo Dicer (DCLs) sobre as moléculas de RNA dos viroides (ITAYA et al., 2001; PAPAEFTHIMIOU et al., 2001; MARTíneZ DE Alba et al., 2002; MAchida et al., 2007; MARTIN et al., 2007). Portanto, deve haver uma interação direta das enzimas relacionadas ao PTGS com o RNA viroidal. Há quatro tipos de DCLs com diferentes localizações subcelulares, sendo que pelo menos uma delas (DCL-1) pode clivar RNAs endógenos que apresentem porções fortemente estruturadas do tipo grampo, similares àquelas presentes nos viroides. Além disso, os siRNAs derivados dos viroides devem funcionar como primers e o RNA genômico viroidal como molde para que uma RNA polimerase dependente de RNA (RdRp), enzima envolvida em mecanismos de silenciamento de RNA em plantas, sintetize moléculas de RNA de fita dupla (dsRNA). A RdRp promove a amplificação do título de dsRNAs na célula, os quais serão substrato para a DCL, resultando na geração em cascata de siRNAs secundários. Gómez et al. (2008) demonstraram que o acúmulo de elevadas concentrações de siRNAs derivados do HSVd em $N$. benthamiana é dependente da atividade da RDR6, uma das RdRp celulares, sugerindo que a maior fração dos siRNAs derivada desse viroide deve ser gerada por meio da atividade da RDR6. Vale ressaltar que siRNAs de diferentes tamanhos têm sido detectados em tecidos de plantas infectadas por viroides (MACHIDA et al., 2007), o que indica a existência de mais de um mecanismo envolvido no silenciamento (TsAgris et al., 2008).
Emuma etapa seguinte, uma das fitas dos siRNAse também dos microRNAs, uma outra classe de pequenos RNAs endógenos que não codificam proteínas, implicados na regulação do desenvolvimento em plantas e outros organismos (RUIZ-FERRER; VOINNET, 2009), são incorporadas ao complexo denominado de RISC (RNA-induced silencing complex). Acreditase que o processo se dá por meio do pareamento de bases do siRNA carreado por RISC com um RNA mensageiro (mRNA) do hospedeiro, interferindo na tradução e induzindo a doença (WANG et al., 2004). Com base nessas suposições, ITAYA et al. (2007) mostraram que siRNAs derivados do PSTVd são biologicamente ativos guiando RISC a degradar uma sequência complementar, no caso o gene da GFP (proteína fluorescente verde utilizada como marcador in vivo) em fusão com uma sequência do PSTVd agro-infiltrado em tomateiros previamente infectados pelo PSTVd, o que promoveu uma redução significativa da fluorescência. Porém, a estrutura secundária do PSTVd resistiu à clivagem por RISC. GómeZ ; PAllás (2007) também demonstraram que formas circulares do HSVd não tiveram decréscimo do seu título quando translocadas para tecidos transgênicos que apresentavam siRNAs.

Esses trabalhos deixam claro que o silenciamento de RNA em plantas deve desempenhar importante papel nos mecanismos de patogenicidade de viroides e também na evolução de suas estruturas secundárias. Vale lembrar, porém, quemRNAs do hospedeiro candidatos, ou seja, queapresentem complementaridade aos siRNAs viroidais ainda não foram identificados. Os resultados de CARBOnell et al. (2008) também apontam para a existência de um complexo RISC, específico aos viroides, que opera em plantas infectadas por esses patógenos. Os autores demonstraram que os sintomas foram reduzidos quando diferentes viroides eram co-inoculadoscom dsRNAshomólogos em hospedeiros suscetíveis, sendo que o mesmo não acontecia coma co-inoculação de dsRNAs heterólogos. A sensibilidade dos viroides (de ambas as famílias) ao complexo RISC ajuda a explicar o fenômeno da proteção cruzada, em que siRNAs derivados de uma estirpe fraca de um determinado viroide (inoculado previamente), dirigiria RISC contra a posterior invasão da estirpe severa. Recentemente, ScHWIND et al. (2009) demonstraram que linhagens de tomateiros transgênicos, transformados com construções que expressam porções de RNA do PSTVd estruturados em grampo, acumularam elevados níveis de siRNAs e apresentaram resistência efetiva ao PSTVd. Além disso, os autores mapearam os pequenos RNAs resultantes do silenciamento e identificaram uma distribuição desuniforme, com uma frequência maior de siRNAs derivados das regiões variável (domínio "V") eterminal direito (domínio "TR") da molécula do PSTVd. Recentemente, DiSERIOetal. (2009), utilizando 
uma moderna e extremamente robusta plataforma de sequenciamento de DNA em larga escala ["Deep Sequencing" (Solexa-Illumina)], analisaram siRNAs derivados de pessegueiros infectados com dois variantes do PLMVd: (i) indutor de clorose extrema (Peach Calico, PC), que apresenta uma inserção de 12 a 13 nucleotídeos, caracterizada como determinante de patogenicidade (MALFITANo et al., 2003); e (ii) indutor de mosaico típico (Peach Mosaic, PM). Observou-se uma prevalência desiRNAs derivados doPLMVd com 21 e 22 nucleotídeos, indicando que DCL-4 e DCL-2, respectivamente, estejam relacionadas comaclivagem das moléculas do PLMVd em ambas polaridades. A ausência de siRNAs derivados do determinante de patogenicidadeindica queé pouco provável aindução de sintomas de clorose extrema via siRNAs (Di SERIO et al., 2009). NAVARRO et al. (2009), utilizando a mesma plataforma de sequenciamento em larga escala, analisaram siRNAs derivados da co-infecção pelo HSVd e Grapevine yellow speckel viroid -1, GYSVd-1 (ambos nucleares) em videira. Os autores verificaram que a grande maioria dos siRNAs foi derivada de regiões específicas (hotspots) do genoma viroidal, tanto de moléculas de polaridade positiva quanto negativa, havendo prevalência de siRNAs provenientes de moléculas de polaridade negativa de ambos os viroides. Além disso, houve prevalência de siRNAs com tamanhos de 21, 22 e 24 nucleotídeos, indicando que diferentes DCLs devem estar relacionadas com a clivagem das moléculas desses viroides em videira.

Os viroides são alvo de silenciamento e, por não codificarem proteínas supressoras desse mecanismo, devem ter garantido sua existência e seu sucesso ao longo da evolução, utilizando exclusivamente uma estratégia baseada em sua sequência e estrutura secundária, o que os tornam significativamente resistentes à degradação mediada pelo silenciamento de RNA (WANG et al., 2004). A compartimentalização em organelas, a simples associação com fatores do hospedeiro e a eficiência na replicação podem ser estratégias de sobrevivência desses patógenos e devem auxiliar os viroides a se proteger de alguma forma dos mecanismos de silenciamento. Outra questão intrigante é que os viroides podem ser alvo da mesma maquinaria de silenciamento que contém enzimas (DCLs) essenciais para sua replicação e processamento (DARòset al., 2006; GómEZ et al., 2009).

Nos últimos anos, houve um avanço considerável no conhecimento das interações moleculares dos viroides com fatores relacionados à replicação, processamento, movimento e patogênese, porém a complexidade do ciclo infeccioso desses minúsculos RNAs indica que muitas outras interações destes patógenos com fatores da célula hospedeira ainda devem ser identificados. O conhecimento atual das interações dos viroides com fatores do hospedeiro é somente a ponta de um gigantesco iceberg que ainda permanece submerso em um oceano de questionamentos.

\section{Fósseis do "Mundo de RNA"}

A descoberta da atividade catalítica, por meio de ribozimas, em alguns RNAs viroidais reforçou a ideia de que previamente ao mundo celular atual, baseado em DNA e proteínas, existiu provavelmente um "Mundo de RNA" em que tanto as macromoléculas que armazenavam como as que expressavam a informação genética eram de RNA (GILBERT, 1986). Os viroides e os VL-satRNAs (RNAs satélites de alguns vírus de plantas que apresentam estrutura viroidal) poderiam ser relíquias dessa era antiga [ver para uma revisão EIRAs et al. (2006a)]. A estrutura dos RNAs do tipo viroide, e em particular seu pequeno tamanho e alto conteúdo de $G+C$, teria permitido superar a baixa fidelidade de cópia dos sistemas replicativos primitivos e, por outro lado, sua estrutura circular teria dispensado os sinais de início e término da replicação. Porém, o argumento que mais reforça esta hipótese é a presença, nos viroides da família Avsunviroidae e em todos os VL-satRNAs, de ribozimas estruturalmente muito simples que poderiam ter catalisado a replicação durante as etapas iniciais da evolução da vida na Terra. Posteriormente, os viroides teriam adquirido dependência de uma célula hospedeira (e os VL-satRNAs, de um vírus auxiliar), convertendo-se assim em parasitas intracelulares. A atividade ribozimática presente em alguns RNAs do tipo viroide seria um vestígio de seu passado evolutivo (DiEnER, 1996, Elena et al., 1991).

Hátambémfortes evidênciasquesustentamahipótese de que cloroplastos são organelas que evoluíram decianobactérias porsimbiose(MARGULIS, 1993; MARTIN, 1999), sugerindo que esses procariontes de vida livre poderiam ter hospedado viroides, principalmente os ancestrais da família Avsunviroidae, anteriormente à colonização das plantas superiores. Isso implica que os membros da família Avsunviroidae sejam os viroides mais antigos (FLores et al., 2000). Análises filogenéticas são consistentes com essas suposições e também sugerem que viroides possam estar presentes atualmente em cianobactérias (ElENA et al., 1991).

Genomas de RNA são capazes de variar e evoluir mais rapidamente que os de DNA. A diferença principal está na existência de tamanhos populacionais muito grandes nos genomas de RNA ena baixa fidelidade de replicação, devido à ausência de atividade corretora nas RNA polimerases e de mecanismos pósreplicativos de reparação que ope-ram em sistemas baseados no DNA. Os vírus de RNA e os viroides se propagam como um conjunto de sequências estreitamente relacionadas, mas não idênticas, formando uma quase-espécie (quasispecies) viral ou viroidal (DOMINGO; Holland, 1994), conferindo plasticidade e 
elevada capacidade de evadir de pressões evolutivas adversas. Esta plasticidade, contudo, tem restrições que impedem a fixação de mutações em regiões da molécula determinantes de algumas funções-chave, como na porção central das estruturas ribozimáticas, onde não há variabilidade (FLORES et al., 2001). Recentemente, demonstrou-se que o CChMVd, membro da família Avsunviroidae, apresenta as maiores taxas de mutação de todas as entidades biológicas conhecidas (GAGO et al., 2009), reforçando a ideia de que os mecanismos de correção de erros durante a replicação foram fatores fundamentais na evolução da complexidade biológica existente na Terra.

\section{AGRADECIMENTOS}

AoDr. T.V.M.FAJARDO (Pesquisador daEmbrapa Uva e Vinho) pela leitura crítica do manuscrito; ao $\mathrm{CNPq}$ pelo financiamento do projeto de pesquisa (proc. 474522/2007-5).

\section{REFERÊNCIAS}

BRANCH, A.D.; BENEFELD, B.J.; ROBERTSON, H.D. Ultraviolet light-induced crosslinking reveals a unique region of local tertiary structure in potato spindle tuber viroid and HeLa 5S RNA. Proceedings of the National Academy of Science of the USA, v.82, p.6590-6594, 1985.

CARBONELL, A.; MARTÍNEZ DE ALBA, A.E.; FLORES, R.; GAGO, S. Double-stranded RNA interferes in a sequence-specific manner with the infection of representative members of the two viroid families. Virology, v.371, p.44-53, 2008.

DARÒS, J.A.; FLORES, R. A chloroplast protein binds a viroid RNA in vivo and facilitates its hammerheadmediated self-cleavage. EMBO Journal, v.21, p.749-759, 2002.

DARÒS, J.A.; FLORES, R. Arabidopsis thaliana has the enzymatic machinery for replicating representative viroid species of the family Pospiviroidae. Proceedings of the National Academy of Science of the USA, v.101, p.6792-6797, 2004.

DARÒS, J.A.; ELENA, S.F.; FLORES, R. Viroids: an Ariadne's thread into the RNA labyrinth. EMBO Reports, v.7, p.593-598, 2006.

DE LA PEÑA, M.; FLORES, R. Chrysanthemum chlorotic mottle viroid RNA: dissection of the pathogenicity determinant and comparative fitness of symptomatic and non-symptmatic variants. Journal of Molecular Biology, v.321, p.411-421, 2002.

DELGADO, S.; MARTÍNEZ DE ALBA, A.E.;

HERNÁNDEZ, C.; FLORES, R. A short double-stranded
RNA motif of Peach latent mosaic viroid contains the initiation and self-cleavage siter of both polarity strands. Journal of Virology, v.79, p.12934-12943, 2005.

DIENER, T.O. Origin and evolution of viroids and viroid-like satellite RNAs. Virus Genes, v.11, p.119-131, 1996.

DING, B. The biology of viroid-host interactions. Annual Review of Phytopathology, v.47, p.105-131, 2009.

DING, B.; ITAYA, A. Viroid: A useful model for studying the basic principles of infection and RNA biology. Molecular Plant-Microbe Interactions, v.20, p.7-20, 2007.

DING, B.; WANG, Y. Viroids: uniquely simple and tractable models to elucidate regulation and cell-to-cell trafficking of RNA. DNA and Cell Biology, v.28, p.1-6, 2009.

DI SERIO, F.; GISEL, A.; NAVARRO, B.; DELGADO, S.; MARTÍNEZ DE ALBA, A.E.; DONVITO, G.; FLORES, R. Deep sequencing of the small RNAs derived from two symptomatic variants of a chloroplastic viroid: implications for their Genesis and for pathogenesis. PLoS One, v.4, p.e7539 (Doi:10.1371/journal.pone.0007539), 2009.

DOMINGO, E.; HOLLAND, J.J. Mutation rates and rapid evolution of RNA viruses. In: MORSE, S.S. (Ed.). Evolutionary Biology of Viruses. New York: Raven Press, 1994. p.171-180.

DUBÉ, A.; BISSAILLO, M.; PERREAULT, J.P. Identification of proteins from Prunus persica that interact with Peach latent mosaic viroid. Journal of Virology, v.16, p.12057-12067, 2009.

EIRAS, M. Identificação e caracterização de viroides e estudo de alguns aspectos da interação de viroides com proteínas do hospedeiro. 2006. 109f. Tese (Doutorado em Agronomia, Área de Fitopatologia). Escola Superior de Agricultura "Luiz de Queiroz", Universidade de São Paulo, Piracicaba, SP. 2006.

EIRAS, M.; DARÒS, J.A.; FLORES, R.; KITAJIMA, E.W. Viroides e virusóides: relíquias do mundo de RNA. Fitopatologia Brasileira, v.31, p.229-246, 2006a.

EIRAS, M.; KITAJIMA, E.W.; FLORES, R.; DARÒS, J.A. Specific interaction in vitro of Potato spindle tuber viroid and Arabidopsis thaliana ribosomal protein L5 and transcription factor IIIA. Fitopatologia Brasileira, v.31, p.S122, 2006b.

EIRAS, M.; KITAJIMA, E.W.; FLORES, R.; DARÒS, J.A. Existence in vivo of the loop E motif in Potato spindle tuber viroid RNA. Archives of Virology, v.152, p.1389-1393, 2007.

EIRAS, M.; NOHALES, M.A.; KITAJIMA, E.W.; FLORES, R.; DARÒS, J.A. Ribosomal protein L5 and transcription 
factor IIIA from Arabidopsis thaliana bind in vitro specifically Potato spindle tuber viroid RNA. Archives of Virology, 2011. (in press)

ELENA, S.F.; DOPAZO, J.; FLORES, R.; DIENER, T.O.; MOYA, A. Phylogeny of viroids, viroid-like satellite RNAs and viroid-like domain of hepatitis delta virus RNA. Proceedings of the National Academy of Sciences of the USA, v.88, p.5631-5634, 1991.

FLORES, R.; DARÒS, J.A.; HERNÁNDEZ, C. The Avsunviroidae family: viroids containing hammerhead ribozymes. Advances in Virus Research, v.55, p.271-323, 2000.

FLORES, R.; HERNÁNDEZ, C.; DE LA PEÑA, M.; VERA, A.; DARÒS, J.A. Hammerhead ribozyme structure and function in plant RNA replication. Methods in Enzymology, v.341, p.540-552, 2001.

FLORES, R.; HERNÁNDEZ, C.; MARTÍNEZ DE ALBA, A.E.; DARÒS, J.A.; DI SERIO, F. Viroids and viroidhost interactions. Annual Review of Phytopathology, v.43, p.117-139, 2005.

FLORES, R.; OWENS, R.A. Viroids. In: MAHY, B.W.J.; VAN REGENMORTEL, M.H.V. (Ed.). Encyclopedia of Virology. Oxford Univ. Press/Elsevier, 2008. p. 332-342.

FLORES, R.; SEMANCIK, J.S. Properties of a cell-free system for synthesis of citrus exocortis viroid. Proceedings of the National Academy of Science of the USA, v.79, p.6285-6288, 1982.

GAGO, S.; ELENA, S.F.; FLORES, R.; SANJUÁN, R. Extremely high mutation rate of a hammerhead viroid. Science, v.323, p.1308, 2009.

GAS, M.E., HERNÁNDEZ, C., FLORES, R., DARÒS, J.A. Processing of nuclear viroids in vivo: an interplay between RNA conformations. PLoS Pathogens, v.3, p.1813-1826, 2007.

GAS, M.E.; MOLINA-SERRANO, D.; HERNÁNDEZ, C.; FLORES, R.; DARÒS, J.A. Monomeric linear RNA of Citrus exocortis viroid resulting from processing in vivo has 5'-Phosphomonoester and 3'-Hydroxyl Termini: implications for the RNAse and RNA ligase involved in replication. Journal of Virology, v.82, p.10321-10325, 2008.

GILBERT, W. The RNA world. Nature, v.319, p.618, 1986.

GÓMEZ, G.; MARTÍNEZ, G.; PALLÁS, V. Viroid-induced symptoms in Nicotiana benthamiana plants are dependent on RDR6 activity. Plant Physiology, v.148, p.414-423, 2008.

GÓMEZ, G.; MARTÍNEZ, G.; PALLÁS, V. Interplay between viroid-induced pathogenesis and RNA silencing pathways. Trends in Plant Science, v.14, p.264-269, 2009. GÓMEZ, G.; PALLÁS, V. Identification of an in vitro ribonucleoprotein complex between a viroid RNA and a phloem protein from cucumber plants. Molecular Plant-Microbe Interactions, v.14, p.910-913, 2001.

GÓMEZ, G.; PALLÁS, V. A long-distance translocatable phloem protein from cucumber forms a ribonucleoprotein complex in vivo with hop stunt viroid RNA. Journal of Virology, v.78, p.10104-10110, 2004.

GÓMEZ, G.; PALLÁS, V. Mature monomeric forms of Hop stunt viroid resist RNA silencing in transgenic plants. Plant Journal, v.51, p.1041-1049, 2007.

GÓMEZ, G.; TORRES, H.; PALLÁS, V. Identification of translocatable RNA-binding phloem proteins from melon, potential components of the long-distance RNA transport system. Plant Journal, v.41, p.107-116, 2005.

GOZMANOVA, M.; DENTI, M.A.; MINKOV, I.N.; TSAGRIS, M.; TABLER, M. Characterization of the RNA motif responsible for the specific interaction of potato spindle tuber viroid RNA (PSTVd) and the tomato protein Virp1. Nucleic Acids Research, v.31, p.5534-5543, 2003.

ITAYA, A.; FOLIMONOV, A.; MATSUDA, Y.; NELSON, R.S.; DING, B. Potato spindle tuber viroid as inducer of RNA silencing in infected tomato. Molecular PlantMicrobe Interactions, v.14, p.1332-1334, 2001.

ITAYA, A.; ZHONG, X.; BUNDSCHUH, R.; QI, Y.; WANG, Y.; TAKEDA, R.; HARRIS, A.R.; MOLINA, C.; NELSON, R.S.; DING, B. A structured viroid RNA is substrate for Dicer-like cleavage to produce biologically active small RNAs but is resistant to RISC-mediated degradation. Journal of Virology, v.81, p.2980-2994, 2007.

KALANTIDIS, K.; DENTI, M.A.; TZORTZAKAKI, S.; MARINOU, E.; TABLER, M.; TSAGRIS, M. Virp1 is a host protein with a major role in Potato spindle tuber viroid infection in Nicotiana plants. Journal of Virology, v.81, p.12872-12880, 2007.

KALANTIDIS, K.; SCHUMACHER, H.T.; ALEXIADIS, T.; HELM, J.M. RNA silencing movement in plants. Biology of the Cell, v.100, p.13-26, 2008.

KOLONKO, N.; BANNACH, O.; ASCHEMANN, K.; HU, K.H.; MOORS, M.; SCHMITZ, M.; STEGER, G.; RIESNER, D. Transcription of Potato spindle tuber viroid by RNA polymerase II starts in the left terminal loop. Virology, v.347, p.392-404, 2006.

LANDRY, P.; PERREAULT, J.P. Identification of a Peach latent mosaic virus hairpin able to act as a Dicer-like substrate. Journal of Virology, v.79, p.65406543, 2005.

MACHIDA, S.; YAMAHATA, N.; WATANUKI, H.; OWENS, R.A.; SANO, T. Successive accumulation of two size classes of viroid-specific small RNA in potato spindle tuber viroid-infected tomato plants. Journal of General Virology, v.88, p.3452-3457, 2007. 
MALFITANO, M.; DI SERIO, F.; COVELLI, L.; RAGOZZINO, A.; HERNÁNDEZ, C.; FLORES, R. Peach latent mosaic viroid variants inducing peach calico (extreme chlorosis) contain a characteristic insertion that is responsible for this symptomatology. Virology, v.313, p.492-501, 2003.

MARGULIS, L. Symbiosis in Cell Evolution. 2.ed. New York: M.H.Freeman, 1993. 452p.

MARTIN, W. A briefly argued case that mitochondria and plastids are descendants of endosymbionts, but that the nuclear compartment is not. Proceedings of the Royal Society of London, v.266, p.1387-1395, 1999.

MARTIN, R.; ARENAS, C.; DARÒS, J.A.; COVARRUBIAS, A.; REYES, J.L.; CHUA, N.H. Characterization of small RNAs derived from Citrus exocortis viroid (CEVd) in infected tomato plants. Virology, v.367, p.135-146, 2007.

MARTÍNEZ DE ALBA, A.E.; FLORES, R.; HERNÁNDEZ, C. Two chloroplastic viroids induce the accumulation of small RNAs associated with posttranscriptional gene silencing. Journal of Virology, v.76, p.13094-13096, 2002.

MARTÍNEZ DE ALBA, A.E.; SAGESSER, R.; TABLER, M.; TSAGRIS, M. A bromodomain-containing protein from tomato specifically binds potato spindle tuber viroid RNA in vitro and in vivo. Journal of Virology, v.77, p.9685-9694, 2003.

MOLINA-SERRANO, D.; SUAY, L.; SALVADOR, M.L.; FLORES, R.; DARÒS, J.A. Processing of RNAs of the family Avsunviroidae in Clamydomonas reinhardtii chloroplasts. Journal of Virology, v.81, p.4363-4366, 2007.

MÜHLBACH, H.P.; SÄNGER, H.L. Viroid replication is inhibited by $\alpha$-amanitin. Nature, v.278, p.185-188, 1979.

NAVARRO, B.; PANTALEO, V.; GISEL, A.; MOXON, S.; DALMAY, T.; BISZTRAY, G.; DI SERIO, F.; BURGYÁN, J. Deep sequencing of viroid-derived small RNAs from grapevine provides new insights on the role of RNA silencing in plant-viroid interaction. PLoS One, v.4, p.e76886 (Doi:10.1371/journal.pone.0007686), 2009.

NAVARRO, J.A.; VERA, A.; FLORES, R. A chloroplastic RNA polymerase resistant to tagetitoxin is involved in replication of avocado sunblotch viroid. Virology, v.268, p.218-225, 2000.

OWENS, R.A. Potato spindle tuber viroid: the simplicity paradox resolved? Molecular Plant Pathology, v.8, p.549560, 2007.

OWENS, R.A.; BLACKBURN, M.; DING, B. Possible involvement of the phloem lectin in long-distance viroid movement. Molecular Plant-Microbe Interactions, v.14, p.905-909, 2001.

PAPAEFTHIMIOU, I.; HAMILTON, A.; DENTI, M.; BAULCOMBE, D.; TSAGRIS, M.; TABLER, M.
Replicating potato spindle tuber viroid RNA is accompanied by short RNA fragments that are characteristic of post-transcriptional gene silencing. Nucleic Acids Research, v.29, p.2395-2400, 2001.

QI, Y.; PELISSIER, T.; ITAYA, A.; HUNT, E.; WASSENEGER, M.; DING, B. Direct role of a viroid RNA motif in mediating directional RNA trafficking across a specific cellular boundary. Plant Cell, v.16, p.1741-1752, 2004.

RODIO, M.E.; DELGADO, S.; DE STRADIS, A.; GÓMEZ, M.D.; FLORES, R.; DI SERIO, F. A viroid RNA with a specific structural motif inhibits chloroplast development. Plant Cell, v.19, p.3610-3626, 2007.

RUIZ-FERRER, V.; VOINNET, O. Roles of plant small RNAs in biotic stress responses. Annual Review of Plant Biology, v.60, p.485-510, 2009.

SCHWIND, N.; ZWIEBEL, M.; ITAYA, A.; DING, B.; WANG, M.B.; KRCZAL, G.; WASSENEGER, M. "'"'RNAi-mediated resistance to potato spindle tuber viroid hairpin RNA construct. Molecular Plant Pathology, v.10, p.459-469, 2009.

TSAGRIS, E.M.; MARTÍNEZ DE ALBA, A.E.; GOZMANOVA, M.; KALANTIDIS, K. Viroids. Cellular Microbiology, v.10, p.2168-2179, 2008.

WANG, M.B.; BIAN, X.Y.; WU, L.M.; LIU, L.X.; SMITH, N.A.; ISENEGGER, D.; WU, R.M.; MASUTA, C.; VANCE, V.; WATSON, J.M.; REZAIAN, A.; DENNIS, E.S.; WATERHOUSE, P.M. On the role of RNA silencing in the pathogenicity and evolution of viroids and viral satellites. Proceedings of the National Academy of Sciences of the USA, v.101, p.3275-3280, 2004.

WANG, Y.; ZHONG, X.; ITAYA, A.; DING, B. Evidence for the existence of the loop E motif of Potato spindle tuber viroid in vivo. Journal of Virology, v.81, p.2074-2077, 2007.

WERNER, R.; GUITTON, M.C.; MÜHLBACH, H.P. Nucleotide sequence of a cathepsin D inhibitor protein from tomato. Plant Physiology, v.103, p.1473, 1993.

WOLFF, P.; GILZ, R.; SCHUMACHER, J.; RIESNER, D. Complexes of viroids with histones and other proteins. Nucleic Acids Research, v.13, p.355-367, 1985.

ZHONG, X.; TAO, X.; STOMBAUGH, J.; LEONTIS, N.; DING, B. Tertiary structure and function of an RNA motif required for plant vascular entry to initiate systemic trafficking. EMBO Journal, v.26, p.3836-3846, 2007.

ZHONG, X.; ARCHUAL, A.J.; AMIN, A.A.; DING, B. A genomic map of viroid RNA motifs critical for replication and systemic trafficking. Plant Cell, v.20, p.35-47, 2008.

Recebido em 24/11/09

Aceito em 30/7/10 